\title{
Correction to: Tobacco Use Among Adults by Sexual Orientation: Findings from the Population Assessment of Tobacco and Health Study, by Wheldon CW, Kaufman AR, Kasza KA, Moser RP. LGBT Health 2018;5(1):33-44. DOI: 10.1089/Igbt.2017.0175
}

In the January 2018 issue of LGBT Health (vol. 5, no. 1; 33-44), the article entitled, Tobacco Use Among Adults by Sexual Orientation: Findings from the Population Assessment of Tobacco and Health Study by C.W. Wheldon et al., required corrections.

The results of the article have been updated in order to comply with the data reporting requirements set forth by the National Addiction and HIV Data Archive Program. Some estimates have been combined or suppressed to prevent deductive disclosure of an individual's identity.

The online version of the article has been corrected to reflect these updates. Due to the number of changes, the original article has been included as supplementary material to this Correction, with each edit noted. The authors wish to apologize for the error. 